\title{
Christian Fix
}

\section{Die fiducie-sûreté}

\section{Eine Untersuchung der französischen Sicherungstreuhand aus deutscher Sicht}

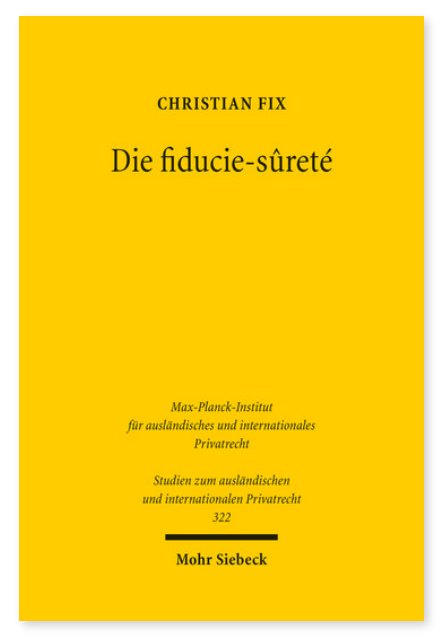

2014. XXIII, 387 Seiten. StudIPR 322

ISBN 978-3-16-153473-7

DOI 10.1628/978-3-16-153473-7

eBook PDF 94,00€

ISBN 978-3-16-153406-5

fadengeheftete Broschur $94,00 €$
Im deutschen Kreditsicherungsrecht kommt der Sicherungstreuhand in Form der Sicherungsübereignung und Sicherungsabtretung eine zentrale Rolle zu. Im Gegensatz dazu war in Frankreich, abgesehen von einigen wenigen Fällen gesetzlicher Normierung mit sehr begrenztem Anwendungsbereich, eine treuhänderische Sicherheit lange Zeit unbekannt. Diesem als unbefriedigend empfundenen Zustand wollte der französische Gesetzgeber im Jahr 2007 durch Einführung der fiducie Abhilfe schaffen, die in der Ausprägung als fiducie-sûreté einer Verwendung als Kreditsicherheit offensteht. Christian Fix unterzieht die neu geschaffene französische Sicherungstreuhand einer Untersuchung aus rechtsvergleichender Perspektive. Die Herausarbeitung der dogmatischen Grundlagen der fiducie-sûreté steht dabei im Vordergrund der Betrachtung. Zugleich liefern die gewonnenen Untersuchungsbefunde wichtige Hinweise für die praktische Verwendung der fiducie-sûreté als Kreditsicherheit.

Christian Fix Geboren 1981; Studium der Rechtswissenschaften an der Albert-Ludwigs-Universität Freiburg i.Brsg.; 2009 Zweite juristische Staatsprüfung; wissenschaftlicher Mitarbeiter am Institut für deutsches und ausländisches Zivilprozessrecht der Universität Freiburg; 2013 Promotion; seit Oktober 2013 im höheren Justizdienst des Landes Baden-Württemberg.
Jetzt bestellen:

https://mohrsiebeck.com/buch/die-fiducie-surete-9783161534737?no_cache=1

order@mohrsiebeck.com

Telefon: +49 (0)7071-923-17

Telefax: +49 (0)7071-51104 